\title{
Mulheres candidatas à vereadora em Umuarama/PR nas eleições de 2016: expectativas e perspectivas da participação feminina na política
}

\author{
Rafael Egidio Leal e Silva ${ }^{1}$ \\ Thais Martini Almeida²
}

\begin{abstract}
RESUMO: Este texto tem por objetivo investigar a percepção das candidatas a vereadora acerca da participação feminina na política local, aproveitando o pleito de 2016. Questionamos a importância da participação das mulheres em cargos políticos em Umuarama-PR, e quais são os fatores que influenciam para a pouca participação das mesmas nos cargos, a partir da análise da fala das candidatas. Observa-se que a participação feminina ainda é muito inferior ao número de homens no poder. No tocante ao pleito eleitoral de 2016, Umuarama contou com 77.467 eleitores, sendo que deste total são aproximadamente $47 \%$ de homens, e $53 \%$ de mulheres. Em relação aos vereadores, foram 121 candidatos disputando 10 vagas na Câmara local, sendo 39 mulheres. A metodologia do projeto realizou a entrevista das candidatas a respeito de sua percepção acerta da expectativa e perspectiva da participação da mulher local. Do total de candidatas, obteve-se o retorno de 11 entrevistas. Além da análise dos dados obtidos, e as entrevistas com as candidatas, o trabalho visa contribuir com a investigação do histórico da participação feminina na Câmara de vereadores local. Observando tamanha desigualdade entre homens e mulheres na política, e considerando a grande participação masculina, nota-se que esta situação apenas é um retrato da nossa sociedade, e percebe-se que a questão de gênero pode influenciar na participação das mulheres em cargos representativos, sendo o sexo feminino como o menos valorizado.
\end{abstract}

Palavras-chave: Eleições. Candidatas. Umuarama. Mulher. Política.

\footnotetext{
${ }^{1}$ Rafael Egidio Leal e Silva é Licenciado em Ciências Sociais (UEM), Mestre em Psicologia (UEM). Docente do Ensino Básico, Técnico e Tecnológico do Instituto Federal do Paraná Campus Umuarama. Pesquisador vinculado ao grupo NEP. Uma versão preliminar desse texto foi apresentada no VIII Seminário Nacional de Sociologia e Política realizado de 17 a 19 de maio de 2017 na UFPR. E-mail: rafael.silva@ifpr.edu.br.

2 Thais Martini Almeida é Aluna do Curso Técnico em Química Integrado ao Ensino Médio, bolsista CNPq/IFPR. Uma versão preliminar desse texto foi apresentada no VIII Seminário Nacional de Sociologia e Política realizado de 17 a 19 de maio de 2017 na UFPR. E-mail: thaismartinialmeida@gmail.com
} 


\title{
Women candidates for councilwoman in Umuarama / PR in the 2016 elections: expectations and perspectives of women's participation in politics
}

\begin{abstract}
This paper aims to investigate the perception of women candidates for women's participation in local politics, taking advantage of the 2016 elections. We question the importance of women's participation in political positions in Umuarama-PR, and what are the factors that influence For the low participation of the same ones in the positions, from the analysis of the speech of the candidates. It is observed that female participation is still much lower than the number of men in power. Regarding the 2016 electoral campaign, Umuarama had 77,467 voters, out of which $47 \%$ were men, and $53 \%$ were women. In relation to city councilors, there were 121 candidates disputing 10 vacancies in the local Chamber, being 39 women. The methodology of the project carried out the interview of the candidates regarding their perception of the expectation and perspective of the participation of the local women. From the total of candidates, the return of 11 interviews was obtained. In addition to the analysis of the data obtained, and the interviews with the candidates, the work aims to contribute to the investigation of the history of female participation in the local council. Observing such inequality between men and women in politics, and considering the great male participation, it is noticed that this situation is only a picture of our society, and it is perceived that the question of gender can influence the participation of women in representative positions, Being the female the less valued.
\end{abstract}

Keywords: Elections. Candidates. Umuarama. Woman. Policy.

- Enviado em 01/05/2017

- Aprovado em 17/05/2017 


\section{INTRODUÇÃO}

O objetivo deste texto é investigar a percepção em relação às expectativas e perspectivas das candidatas a vereadora nas Eleições de 2016 acerca da participação feminina na política local do município de Umuarama, localizada no noroeste do Estado do Paraná. Se por um lado podemos notar que há um discurso que chama a atenção para a necessidade da maior participação da mulher na política, por outro lado não podemos deixar de considerar as barreiras sociais invisíveis que dificultam que a mulher se torne efetivamente uma agente política em igualdade de condições com os candidatos nas disputas eleitorais.

Assim sendo, como a mulher percebe tal diferença, especialmente a candidata a um cargo local em um contexto local e interiorano? A candidata é também um agente de denúncia acerca do domínio masculino local? Tais questões estão postas neste trabalho, que tem como finalidade também de dar voz para as estas mulheres. Questionamos a importância da participação das mulheres em cargos políticos em Umuarama-PR, e quais são os fatores que influenciam para a pouca participação das mesmas nos cargos, a partir da análise da fala das candidatas.

Investigar a mulher candidata a vereadora, em suas perspectivas e expectativas tem sua importância por colocar a situação da participação da mulher na política em sua realidade, especialmente a realidade local e interiorana. Afinal, se por um lado há tanto campanhas midiáticas que tratam da valorização da mulher na política, quanto a cota partidária de participação da mulher a qual falaremos abaixo, por outro lado, devemos investigar a percepção da mulher que se predispõe à candidatura de um cargo relevante no município, e, além da busca de votos, deve superar a invariável circunstância de ser mulher em contextos ainda predominantemente masculinos, como a política local.

A cidade de Umuarama é também interessante em relação à perspectiva da pesquisa da relação gênero e política. Localizada no extremo noroeste do Estado do Paraná, é uma cidade de médio porte com população estimada em 109.132 habitantes, tendo sido elevada à condição de município em 1960. Distante 580 quilômetros da capital Curitiba, e a cerca de 100 quilômetros do Paraguai, trata-se, portanto, de uma cidade da região de fronteira do Estado brasileiro. Importante cidade regional, sendo inclusive a sede de Região Metropolitana (a quarta estabelecida no Paraná), é também conhecida como "Capital da Amizade". Mas também possui um outro apelido curioso na região: "mulherama". Mesmo cidades como Londrina e Maringá (distantes respectivamente cerca de 300 e 180 quilômetros de Umuarama) é comum ouvir esta alcunha, sempre no sentido da quantidade de mulheres (e mulheres bonitas) que Umuarama teria. $\mathrm{O}$ senso comum regional chega a dizer que esta expressão existiria por conta do número excessivamente superior de mulheres em relação aos homens no município, em termos habitacionais. Dentro de Umuarama, a "mulherama" é também muito usada, muitas vezes em tom pejorativo, mas muitas vezes também em tom 
elogioso, significando não apenas a quantidade de mulheres, mas também a sua beleza, considerando que muitas belas - e famosas - modelos paranaenses seriam de origem umuaramense. São amplamente conhecidos e emblemáticos na cidade os casos de Caroline Correa, modelo que fez figuração em filmes como Star Wars III e Velozes e furiosos: desafio em Toquio, e o recente caso da Miss Brasil Raíssa Santana (que nasceu na Bahia, e apenas com 6 anos de idade passou a morar em Umuarama) que disputou o título de Miss Universo neste ano de 2017. O caso da modelo Elaine Lopes da Silva (1983-2007) que foi Miss Umuarama (2002) e Miss Paraná (2003) e que faleceu em um acidente automobilístico chega a ser catártico, pois o jornalismo local indica o seu túmulo como o mais visitado no cemitério da cidade.

Quem visita a cidade, no entanto, nota um outro fenômeno que é muito comum nos munícipios do interior: a incorporação do nome da cidade (ou parte dele) nas casas comerciais. Algo que em Maringá acontece com a adoção do sufixo "ingá", na cidade de Paranavaí (outra importante cidade do noroeste do Paraná, distante cerca de 150 quilômetros de Umuarama) com a adoção do sufixo "ivaí". No caso de Umuarama, é amplamente usado pelo comércio citadino o sufixo "rama", em empresas como "Autorama", "Motorama", "Placarama", "Oxirama", "Gelorama", entre muitas outras, indicando ao mesmo tempo um determinado objeto (o automóvel, o motor, a placa, o oxigênio, o gelo, etc.) e a cidade "Umuarama". Como indicamos, esta é uma prática comum na região. Mas não há uma "mulheringá", muito menos uma "mulherina" ou "mulherivai". Apenas "mulherama". Será que este apelido não pode nos ajudar a refletir sobre a condição da mulher em Umuarama? Se há um claro indício (regional inclusive) de objetificação da mulher de Umuarama, como isto pode se materializar na política local?

Assim sendo na primeira parte deste artigo trataremos da relação da mulher e a política e também da situação do pleito eleitoral em Umuarama de 2016. Na sequencia, apresentaremos a pesquisa realizada com as candidatas ao cargo de vereadora, bem como o resultado de suas entrevistas.

A diferença entre os gêneros ocorre não apenas no trabalho ou nas questões culturais, mas também nos aspectos políticos em nossa sociedade, interferindo diretamente em cargos representativos e/ou de lideranças. Na história, as mulheres eram/são "conhecidas" como menos importantes que os homens por serem consideradas o "sexo frágil" ou até mesmo incapazes de ocuparem o lugar de um homem na sociedade. A exclusão da mulher na vida política é um reflexo da exclusão da mulher na sociedade e na ausência de reconhecimento como sujeito, baseado em grande medida no predomínio da figura do homem, seja no aspecto social, político ou econômico (VAZ, 2008). Atualmente, é notória a inferioridade da participação feminina como autoridade nos cargos políticos em relação ao homem. Na política, nota-se a baixa participação das mulheres, e isso se deve ao fato de que o homem sendo um ser "público", seu lugar na sociedade é nas lideranças, enquanto a mulher, é vista como submissa ao homem, assim, sempre é associada com o lar, família, filhos, se tornando um ser "particular", um ser não notado 
pela sociedade. Essa exclusão é iniciada dentro de casa, onde geralmente possui uma ideologia patriarcal, em que os homens possuem o "Poder" do lar, enquanto a mulher possui as tarefas do lar. Assim, conforme Haraway:

Além do trabalho assalariado, a divisão de trabalho por gênero incluía também as categorias de trabalho excluídas e não historicizadas em Marx e Engels, isto é, ter e criar crianças, cuidar dos doentes, cozinhar, o trabalho doméstico e trabalhos sexuais como a prostituição, de maneira a trazer gênero e a situação específica da mulher para o centro da análise materialista histórica. (HARAWAY, 2004, p. 228)

Desta forma, a organização social patriarcal em torno da sociedade de classes impôs à mulher um determinado local na sociedade, muito distante das tomadas de decisões e do poder. De acordo com Sow (2010), foi através do movimento feminista que o conceito patriarcal, que condicionava a mulher ao cuidado doméstico, restrito ao lar e à procriação, foi questionado. E tal questionamento configura-se em momento fundamental para o desenvolvimento da cidadania brasileira.

O governo da atualidade, por possuir um percentual maior de homens do que de mulheres, pode ser considerado um governo de homens e para homens, onde as mulheres não possuem muita voz, e até mesmo nenhuma voz. A igualdade formal entre os homens e as mulheres tende a dissimular que, sendo as coisas em tudo iguais, as mulheres ocupam sempre as posições menos favorecidas. Por exemplo, sendo embora verdade que as mulheres estão cada vez mais representadas em funções públicas, são sempre as posições mais baixas e mais precárias que thes são reservadas (BOURDIEU, 2010). E isto porque há a fala comum de que a avaliação de um candidato pelo eleitor deve se passar não pelo gênero (ou etnia), mas principalmente pela competência. No entanto, o discurso da "competência" esconde uma série de atributos masculinos, conforme Bourdieu, ao afirmar que:

Para chegar realmente a conseguir uma posição, uma mulher teria que possuir não só o que é explicitamente exigido pela descrição do cargo, como também todo um conjunto de atributos que os ocupantes masculinos atribuem usualmente ao cargo, uma estatura física ou aptidões, como a agressividade, a segurança, a 'distância em relação ao papel', a autoridade dita natural, etc., para as quais os homens foram preparados e treinados tacitamente enquanto homens. (BOURDIEU, 2010, p. 78)

No mesmo sentido, Mota \& Biroli (2014), ao analisar o gênero na eleição presidencial de 2010 também perceberam que:

As alternativas para as mulheres são adequar-se ao perfil "feminino" e desenvolver sua atuação política dentro dos limites do que é entendido como uma atuação "feminina" - o que pode ser feito estrategicamente - ou projetar sua ação e seu perfil para fora desses limites, o que por um lado pode lhes proporcionar um maior acesso às posições centrais, ao lançar-se para áreas e formas de atuação tidas como "masculinas", mas por outro pode 
marcá-las negativamente, como "desviantes". Em um e outro caso, os custos do "gênero" se impõem. (MOTA \& BIROLI, 2014, p. 207)

Ou seja, o gênero é um importante quesito para a estratégia eleitoral, e a mulher candidata deve se posicionar estrategicamente em relação à sua condição feminina. Mas como a mulher candidata estabelece esta percepção? Embora nosso trabalho não tenha realizado essa questão de modo específico, é uma interessante questão, especialmente na seara local.

No Brasil foi apenas no ano de 1932, através do decreto o. 21.076, que foi instituído o direito do voto para homens e mulheres do país, para ambos possuírem o poder de eleger seus governantes. Mesmo sendo maioria nos quadros demográficos, as mulheres representam $50,7 \%$ da população brasileira, e $51,2 \%$ do eleitorado nacional, mas não ultrapassando $10 \%$ dos cargos legislativos. Deste modo, a participação das mulheres na política após 85 anos do sufrágio feminino ainda é demasiadamente inferior à participação dos homens no poder. A participação das mulheres na política cresceu desde o ano de 1932, mas ainda está longe do ideal. O quadro de exclusão das mulheres desse espaço público é grave. Apenas 15 países apresentam uma participação de mulheres na Câmara dos Deputados superior a 30\%. O Brasil encontra-se no grupo de 70 países com pior desempenho, inferior a 10\%. As mulheres não são levadas a sério em locais de poder e as demandas feministas são ridicularizadas como absurdas, ou se tornam alvo de piadas (engraçadas apenas para as pessoas insensíveis às dificuldades enfrentadas pela mulher no seu cotidiano).

Os partidos políticos ainda não entendem a necessidade da participação feminina efetiva, mas apenas como uma formalidade para se cumprir cotas eleitorais. Segundo uma pesquisa mostrada no livreto “MAIS MULHERES NA POLÍTICA" (s.d.), realizada pelo Senado Federal, o Brasil ocupa o $156^{\circ}$ no ranking de $188^{\circ}$ países de acordo com a quantidade de mulheres no poder. No mundo, nas câmaras e nos senados, em cerca de 46.089 homens e mulheres, $79,1 \%$ são ocupados por homens e $20,9 \%$ são ocupados por mulheres. E a média no Brasil é de 8,6. Devido a tais resultados, atualmente o Brasil tem adotado por via legal, o aumento da participação das mulheres na política. Desta forma, a Lei $9.504 / 97$, no artigo 10, §3으, a qual declara que é necessário em um partido ou coligação ter suas vagas de 30\% a 70\% para candidatura de cada sexo, para incentivar a participação feminina na política. Mesmo após esta lei, os índices das mulheres se candidatando e principalmente eleitas ainda são muito pequenos.

No município de Umuarama, esta situação não é diferente. Ao serem analisadas eleições anteriores, torna-se clara a pouca participação das mulheres no poder legislativo da cidade, observando dentre as três últimas eleições, obtivemos apenas uma mulher escolhida para o cargo de vereador, notando que durante a legislatura de 2012 a 2016 não havia nenhuma mulher neste cargo. No ano 2000, foram 183 candidatos, dos quais, 39 eram mulheres, ou seja, 21\%; no ano 2004, tivemos 107 candidatos, 
sendo 24 mulheres (22\%); no ano 2008, 113 se candidataram, com 21 mulheres (18\%); finalmente, em 2012, foram 137 candidatos, sendo 40 mulheres candidatas (29\%). Um dado curioso nas eleições de 2012 apontou que a primeira colocada entre as mulheres se encontrou no $30^{\circ}$ lugar entre os outros candidatos, e invertendo este gráfico, e analisando os últimos 30 candidatos, se encontram dentre eles 21 mulheres, sendo então mais da metade das mulheres participantes.

No tocante ao pleito eleitoral de 2016, Umuarama teve 77.467 eleitores, sendo que deste total são aproximadamente $46,5 \%$ de homens, e $53,3 \%$ de mulheres. Nas estatísticas eleitorais chama a atenção o fato da maior parte do eleitorado ter o Ensino Fundamental incompleto, com 25,5\%, e Ensino Fundamental completo com $8,47 \%$. Analfabetos e pessoas que "leem e escrevem" somam aproximadamente $14 \%$. Uma alta parcela do eleitorado umuaramense não tem o Ensino Médio Completo, com 22,56\%, e completaram este grau de Ensino 18,11\% do eleitorado. Eleitores com Ensino Superior somam 6,34\%, e que ainda não completaram este grau de ensino perfazem 4,99\% do eleitorado. Foram 05 candidatos a prefeito e 122 candidatos a vereador nesta eleição de 2016 (que disputaram 10 vagas na câmara local), sendo que 40 mulheres se candidataram (33\%). As candidaturas de vereadores estão agrupadas nos seguintes grupos de coligação: 1) Aliança por Umuarama (PMDB /PDT / PR / PMB / PROS /PRB /PT do B /PSL /SD /PSDB); 2) Umuarama em boas mãos (PRP / PTB / PPL); 3) Honestidade para trabalhar (PPS /PSC /PSD /PHS); 3) Participação popular para acertar (PSB /PSDC /PTN); 4) Aliança por Umuarama (DEM / PTC); 5) Partido Verde, PV; 6) Partido dos Trabalhadores, PT; 7) Partido da Mobilização Nacional, PMN.

No resultado final da eleição, foram duas candidatas eleitas, fato inédito na cidade: Ana Novais (PPL) e Maria Ornelas (PTN) com respectivamente 1.621 e 889 votos da população de Umuarama. Importante mencionar que a câmara foi renovada em $80 \%$, e não apenas em termos de pessoas, mas em termos de perfil. Na legislatura 2012-2016, todos os vereadores eram homens; 09 se consideravam brancos, 01 se considerava pardo. Metade dos vereadores possuíam Ensino Médio Completo; 04 possuíam Ensino Superior Completo e 01 possuía Ensino Superior incompleto. Da nova configuração, são 08 homens e 02 mulheres. São também dois pretos eleitos. A nova legislatura mantém um alto nível de escolaridade: são 07 eleitos com nível Superior Completo; 01 com Ensino Superior incompleto, 02 com Ensino Fundamental Completo (os dois candidatos eleitos pretos), o que pode indicar um desejo de mudança a respeito dos representantes locais, por parte da população. E o que dizem as mulheres que foram candidatas? 


\section{Entrevistas: resultados e discussões.}

A fim de apresentarmos os resultados e discussões, é necessário expor, primeiramente, uma dificuldade que esta pesquisa enfrentou: o tempo exíguo para a realização das entrevistas, e as circunstância de ser realizado no contexto da eleição. Conforme a Resolução n. 23.450 do Tribunal Superior Eleitoral, no ano de 2016 o período de campanha foi reduzido para 45 dias (nos rádio e TVs a propaganda gratuita iniciou em 26 de agosto, com 37 dias anteriores à eleição), o que significou atividades bastante intensas para os candidatos e candidatas. A ideia da pesquisa era também que as entrevistas acontecessem durante o período de campanha, para que as respostas também fossem de um grupo de identidade em comum, ou seja, de candidatas ao cargo de vereadora nas eleições municipais de 2016, e não a "candidata derrotada" ou a "candidata vitoriosa", caso a entrevista acontecesse após a data das eleições. Claro que por se tratar de candidatas em campanha, é esperado que seu discurso seja amenizado, em termos de suas estratégias eleitorais, como discutimos acima, mesmo que as entrevistas tenham sido feitas de forma anônima.

Optou-se por enviar a pesquisa por correio eletrônico e pelos contatos nas redes sociais das candidatas, em formulário da plataforma Google. Desta forma, de 40 candidatas obtivemos 11 respostas preenchidas, o que consideramos um bom retorno, devido às circunstâncias da pesquisa. O questionário continha duas partes: uma parte com a finalidade de traçar o perfil das candidatas que participaram da pesquisa, e uma parte com perguntas abertas a respeito de sua percepção em relação à participação efetiva na política local umuaramense. Apresentaremos a seguir os dados obtidos com o questionário, e, na sequência, as respostas acerca da percepção da participação feminina na política.

\section{1) Perfil das candidatas.}

Para os fins desta pesquisa, o perfil das candidatas priorizou idade, família e escolaridade. Através destes dados, podemos traçar um perfil médio sobre as candidatas do município de Umuarama. Podemos também pensar que os dados a respeito da ocupação laboral e religiosidade das candidatas seriam de grande valia para traçar um perfil mais completo, o que foi descartado para que a pesquisa pudesse ser realizada de forma mais rápida pela participante, considerando que nosso maior interesse se concentrava nos campos de respostas abertas. No entanto, são variáveis que podemos incluir em versões futuras em pesquisas semelhantes nas próximas eleições.

Com relação ao nascimento, as dez respostas obtidas podem ser visualizadas na tabela a seguir: 
Tabela 1 - Ano de nascimento das candidatas

\begin{tabular}{l|l}
\hline Ano & Número de candidatas \\
\hline 1986 & 2 \\
\hline 1977 & 1 \\
\hline 1976 & 1 \\
\hline 1970 & 1 \\
\hline 1968 & 1 \\
\hline 1966 & 1 \\
\hline 1965 & 1 \\
\hline 1964 & 1 \\
\hline 1957 & 1 \\
\hline
\end{tabular}

Fonte: os autores.

Podemos perceber que a idade das candidatas varia entre os 30 e 60 anos, sendo que a maioria possui mais de quarenta anos, o que indica que uma candidatura não é procurada por mulheres jovens, mas por mulheres com certa experiência de vida.

Com relação à estrutura familiar, onde obtivemos 11 respostas, 6 candidatas são casadas, 4 solteiras e uma divorciada, sendo que 8 candidatas são mães, enquanto 3 não possuem filhos. Com relação ao número de filhos, uma candidata possui um filho, uma possui 2 filhos, 4 candidatas possuem 3 filhos, e uma candidate possui 4 filhos. Pensando na idade das candidatas, inferimos que se tratam de mulheres experientes e com certa estabilidade nos lares, com famílias constituídas, mostrando que a política também deve ser uma decisão madura em suas vidas.

Em relação à escolaridade, onde obtivemos 11 respostas, o resultado está exposto na tabela abaixo:

Tabela 2 - Nível de escolaridade das candidatas

\begin{tabular}{l|l}
\hline Nível & Número de candidatas \\
\hline Ensino Fundamental completo & 2 \\
\hline Ensino Médio incompleto & 1 \\
\hline Ensino Médio completo & 1 \\
\hline Ensino Superior incompleto & 1 \\
\hline
\end{tabular}




\begin{tabular}{l|l}
\hline Ensino Superior completo & 3 \\
\hline $\begin{array}{l}\text { Pós-graduação concluída (especialização, } \\
\text { mestrado ou doutorado) }\end{array}$ & 3 \\
\hline
\end{tabular}

Fonte: os autores.

Outro dado obtido é que das 11 candidatas entrevistadas, todas frequentaram a maior parte de sua formação em instituições públicas. Percebemos então que há a presença de uma alta escolarização entre as candidatas, considerando que a maioria possui ensino superior e/ou pós-graduação completa.

Assim, o perfil das candidatas nos motra mulheres com mais de 30 anos, com família estabilizada e alto grau de escolarização, o que é um perfil relevante para a ocupação de cargos públicos eletivos. No entanto, como estas mulheres percebem a política local?

\section{2) Percepção acerca da participação feminina no município de Umuarama.}

Para os objetivos traçados para este artigo, faremos a exposição da segunda parte do questionário, de perguntas abertas, que foram as seguintes:

1- $\quad$ O que a levou a se candidatar para o cargo de vereador no município?

2- Em sua opinião, qual a importância da participação da mulher na política de Umuarama?

3- $\quad$ Em sua opinião, a participação da mulher na política umuaramense é baixa? (Resposta sim ou não).

4- Em caso de concordância com a afirmação anterior, quais fatores você considera que fazem com que a participação da mulher na política seja baixa?

5- $\quad$ Em sua opinião, como criar na câmara e na sociedade a ideia de necessidade da mulher na participação da política na cidade?

6- Quais projetos você julga ser necessários para a melhoria da qualidade de vida da mulher em Umuarama?

Importante aqui mencionarmos que das 11 candidatas que se dispuseram a responder o questionário, 09 estavam disputando sua primeira eleição. Em relação à filiação partidária, 04 candidatas estão filiadas há menos de 06 meses; 03 candidatas estão filiadas há um ano; 01 candidata está filiada há 2 anos; 01 há 4 anos; 01 há 08 anos e 01 há 19 anos. Ou seja, percebemos aqui que a maior parte das respostas veio de iniciantes na política, inclusive de militância partidária. Talvez aqui abra-se um novo campo de questionamentos: o resultado eleitoral das mulheres também pode estar condicionado à uma 
baixa participação na militância partidária? Ou ainda, quais os fatores que impedem a mulher de uma maior, ou mais constante militância política? Com relação à primeira pergunta, obtivemos as seguintes respostas:

Tabela 3 - O que a levou a se candidatar para o cargo de vereador no município?

\begin{tabular}{l|l}
\hline 1 & A vontade de buscar a melhoria que nescessita a população de nosso município e seus distritos \\
\hline 2 & Ter a ser a oportunidade de fazer política de maneira diferente do que se vê. \\
\hline 3 & Luta pelo direito da população \\
\hline 4 & Fui convidada para preencher a cota de mulheres candidatas \\
\hline 5 & A falta de representação feminina no Poder Legislativo e ser uma eterna inconformada com as coisas. \\
\hline 6 & $\begin{array}{l}\text { Vivo também pelas mesmas situações da população resolvi me.dispor a lutar pelo povo porq ficar em } \\
\text { casa só reclamando não adianta a resolver nada }\end{array}$ \\
\hline 7 & Mudança \\
\hline 8 & Me sinto apta pra lutar pelas causas sociais do minicípio \\
\hline 9 & Ajudar o povo \\
\hline 10 & Por que acho que a mulher precisa mostrar o seu valor. \\
\hline 11 & Procurar melhorar o distrito que moro (Santa Eliza). \\
\hline
\end{tabular}

Fonte: os autores.

Percebemos que boa parte das respostas constituem o discurso político em época de campanha: ajudar o povo e os necessitados, lutar pelos direitos, fazer política de modo diferente, mudança. Interessante que a resposta 04 nos diz diretamente que foi convidada a preencher a cota partidária. As respostas 05 e 10 mostram que são candidatas preocupadas com a participação feminina na política, ou seja, que a questão de gênero é minoritária, mas que está presente em algumas candidatas. Vejamos o resultado da próxima pergunta:

Tabela 4 - Em sua opinião, qual a importância da participação da mulher na política de Umuarama?

\begin{tabular}{l|l}
\hline 1 & $\begin{array}{l}\text { É de imensa importância, já que os ideais de uma mulher diferem em determinados aspectos dos ideais } \\
\text { masculinos, desde o método de pensar até a forma de agir }\end{array}$ \\
\hline 2 & $\begin{array}{l}\text { Muito importante, pois a mulher não tem representação na Câmara Municipal, de modo que suas } \\
\text { contribuições não são ouvidas nas decisões políticas nos últimos anos. }\end{array}$ \\
\hline 3 & Pelo afeto materno a mulher tem mais visão geral da humanidade a mulher enxerga com o coração \\
\hline
\end{tabular}




\begin{tabular}{l|l}
\hline 4 & Pela igualdade em relação aos homens \\
\hline 5 & $\begin{array}{l}\text { De fundamental importância, tendo em vista que a mulher tem o lado mais humano, mais coração e } \\
\text { consegue fazer várias coisas ao mesmo tempo. }\end{array}$ \\
\hline 6 & E Fundamental porq nos mulheres agimos mais com coração e amor no que fazemos é não. Por interesse \\
\hline 7 & Importantíssima \\
\hline 8 & A mulher tem mais audácia, mais cautela, mais sensibilidade \\
\hline 9 & Ver a necessidade do povo umuaramense \\
\hline 10 & Acho muito importante para demonstrar a nossa importância dentro da sociedade umuaramense. \\
\hline 11 & $\begin{array}{l}\text { Melhorar a Câmara que sempre estão os mesmos candidatos e não procuram melhorar a situação } \\
\text { política, partidária e como são trabalhados os votos dos que são eleitos, pois falta pessoas honestas e } \\
\text { talvez a mulher que é mais sensível possa fazer a diferença na política e na câmara. }\end{array}$
\end{tabular}

Fonte: os autores.

Podemos perceber que a importância da mulher na política local está vinculada à noção de senso comum de que a mulher é mais sentimental, que a mulher pensa e age diferente do homem, que a mulher não age por interesse e sim por emoção ou pelo coração,a mulher é mais honesta, e também porque a mulher consegue fazer mais coisas ao mesmo tempo, ou até mesma pela igualdade em relação aos homens. É interessante que a questão da representatividade feminina apareça em poucas respostas, como a resposta 02: se a mulher não tem representante na câmara, ela não é ouvida, como ocorreu nas legislaturas sem representação. A resposta 10 ressalta a importância da mulher em cargos de poder junto à cidade e à comunidade de Umuarama. Vemos também que são respostas minoritárias, mas que aparecem no discurso das candidatas.

A terceira pergunta admitia apenas as respostas SIM ou NÃO para a pergunta: Em sua opinião, a participação da mulher na política umuaramense é baixa? Neste quesito, todas consideraram que SIM, a participação feminina na política (e não apenas na câmara) é baixa. E consideremos aqui que das 11 respostas estão tanto mulheres iniciantes, como experientes na política local. A próxima pergunta, aproveitando desta resposta é a seguinte:

Tabela 5 - Em caso de concordância com a afirmação anterior, quais fatores você considera que fazem com que a participação da mulher na política seja baixa?

\begin{tabular}{l|l}
\hline 1 & $\begin{array}{l}\text { A presença de conservadores na sociedade e no atual cenário político, que passam uma imagem de que } \\
\text { o sexo feminino não é capacitado à política }\end{array}$ \\
\hline 2 & $\begin{array}{l}\text { Falta de boas candidatas (muitas se candidatam p cumprir a legislação) e falta de investimentos e } \\
\text { organização das campanhas a fim de competir de igual p igual com as dos homens. }\end{array}$ \\
\hline
\end{tabular}




\begin{tabular}{|c|c|}
\hline 3 & $\begin{array}{l}\text { Axo que a baixa que a população não abriu o olha que a mulher tem mais capacidade luta mais pelo } \\
\text { povo }\end{array}$ \\
\hline 4 & Pela falta de interesse das próprias mulheres \\
\hline 5 & $\begin{array}{l}\text { Falta de coragem, falta de disponibilidade, falta de interesse já que a política para a maioria não é } \\
\text { agradável e deixou um desgaste muito grande no país. }\end{array}$ \\
\hline 6 & $\begin{array}{l}\text { Muita falta de informação para com as mulheres da cidade sobre política e Falta de interresse tambm da } \\
\text { maioria em saber mais sobre o assunto }\end{array}$ \\
\hline 7 & Não é levada a sério na sua capacidade \\
\hline 8 & falta de Reconhecimento \\
\hline 9 & $\begin{array}{l}\text { Pessoas acreditam q a mulher nao tenha a mesma capacidade em fazer a politica pois Na realidade nao e } \\
\text { fazer politica e sim ver as necessidade do povo e de umuarama }\end{array}$ \\
\hline 10 & $\begin{array}{l}\text { A participação da mulher na política esta muito aquém do nosso número na sociedade, isso por que as } \\
\text { próprias mulheres não dão apoio para esta participação, me parece que não acreditam nelas mesmas e } \\
\text { muito menos em outras mulheres para resolver os problemas políticos. As mulheres não sabem a força } \\
\text { que tem! Outro motivo é machismo que impera em nossa sociedade, muitos homens não acreditam que } \\
\text { as mulheres entendam de política, pois acham que isso é coisa de homens! Tudo isso acaba } \\
\text { desestimulando a participação das mulheres na política. }\end{array}$ \\
\hline 11 & $\begin{array}{l}\text { Os que estão lá, entram porque compram votos e são sempre eleitos, aqui mesmo tendo candidatos os } \\
\text { eleitores votam em pessoas de fora, falta honestidade tanto da parte dos políticos como dos eleitores. }\end{array}$ \\
\hline
\end{tabular}

Fonte: os autores.

Observamos aqui que há muito presente o discurso que a sociedade não entendeu ou percebeu a capacidade da mulher, ou que a mulher não percebeu as suas capacidades, e por isso não participa da política. Mas temos também a presença de algumas respostas interessantes, como a 02: além de muitas candidatas apenas cumprirem a cota partidária, o próprio partido ou coligação não investe na candidata porque não acredita nela. A resposta 06 demonstra que há falta de informações e falta de interesse para com a participação feminina. A resposta 10 traz o elemento do machismo presente na sociedade, especialmente em Umuarama, e, em tom de desabafo nos informa que "muitos homens não acreditam que as mulheres entendam de política, pois acham que isso é coisa de homens!" o que gera desestimulação nas mulheres do município Ou seja, a política local é um ambiente hostil para a mulher. A resposta 11 nos informa que o jogo político de "compra" de votos (ou talvez até o clientelismo por parte dos políticos de longa carreira) impede que outros candidatos consigam se estabelecer na política local, principalmente as mulheres. A próxima questão foi respondida da seguinte forma: 
Tabela 6 - Em sua opinião, como criar na câmara e na sociedade a ideia de necessidade da mulher na participação da política na cidade?

\begin{tabular}{|c|c|}
\hline 1 & $\begin{array}{l}\text { Influenciar para que mulheres com bons ideais, possam expor suas idéias, e mostrar a elas que são } \\
\text { capazes, através de reuniões nas associações de moradores, e ir em busca de uma associação que tenha } \\
\text { como função influenciar a participação da mulher na política. }\end{array}$ \\
\hline 2 & $\begin{array}{l}\text { Conscientização da população sobre a importância da presença e contribuições da mulher nas decisões } \\
\text { políticas. Ela está presente em outros setores com sucesso. }\end{array}$ \\
\hline 3 & $\begin{array}{l}\text { Incentivo mostrando que a mulher e capacitada pois tem direito a vaga de cadeiras pois votamos e } \\
\text { temos direito }\end{array}$ \\
\hline 4 & $\begin{array}{l}\text { Acho que uma vereadora eleita, deve sempre fazer reuniões com mulheres empresárias, donas de casa, } \\
\text { artesãs, vendedoras, enfermeiras etc. E dizer da importância de cada uma na política ou seja que a } \\
\text { mudança depende de cada um de nós. }\end{array}$ \\
\hline 5 & $\begin{array}{l}\text { Primeiro precisa chamar e convencer a participação delas nos debates públicos. A mulher se sai bem em } \\
\text { todos os setores e na política. se quiser, dá um show. Portanto, se puxar as mulheres para eventos que } \\
\text { discutam as ações da comunidade, talvez comece a despertar a vontade de fazer política. }\end{array}$ \\
\hline 6 & $\begin{array}{l}\text { Criando dentro dos partidos políticos grupos de mulheres para integra -las no meio .. E na Câmara } \\
\text { mulher eleita mostrar q somos sim capazes de fazer a diferença na Política com trabalhos honestos e } \\
\text { viáveis para a população }\end{array}$ \\
\hline 7 & Sendo participativa junto a comunidade \\
\hline 8 & Participando e demonstrando a diferença passo a passo \\
\hline 9 & $\begin{array}{l}\text { Uma maneira de incentivo é que sejam realizadas campanhas de incentivo à participação das mulheres } \\
\text { na política, através de rádio e televisão, a fim de despertar as condições para que elas participem dos } \\
\text { processos decisórios do país. }\end{array}$ \\
\hline 10 & $\begin{array}{l}\text { A participação política da mulher no Brasil por meio do voto é recente, talvez por isso a dificuldade } \\
\text { maior que há no interior de se ter mulher na política. A participação da mulher está em todas as áreas de } \\
\text { trabalho e com certeza a mulher na política faria muita diferença, principalmente em áreas que em } \\
\text { nosso município e precária. }\end{array}$ \\
\hline
\end{tabular}

Fonte: os autores.

Neste quesito obtivemos 10 respostas, conforme a tabela acima. Observamos que há uma tendência (coerente com as respostas anteriores) que a maior necessidade da participação feminina é uma questão individual, ou seja, cada mulher mostrando sua importância na comunidade e na política é que vai gerar a sua importância. Ou então há a necessidade de campanhas que demonstrem a necessidade da participação feminina. E podemos perceber que esta conscientização (tanto através de exemplos, como de campanhas) é bastante enfatizado nas falas, ou seja, que a visão generalizada acerca da mulher na política em nível local é bastante precária, e deve ser muito estimulada. E claro, a candidata sente isso na pele, tanto pela falta de apoio, e pela perspectiva da falta de votos. Finalmente a última questão solicitava: 
Tabela 7 - Quais projetos você julga ser necessários para a melhoria da qualidade de vida da mulher em Umuarama?

\begin{tabular}{l|l}
\hline 1 & $\begin{array}{l}\text { Uma associação com cursos especializados para capacitação das mulheres para ocupar as mais } \\
\text { variadas áreas no município, desde a administração até a construção civil, ou seja, encorajar as } \\
\text { mulheres a cada vez mais buscarem a igualdade social. }\end{array}$ \\
\hline 2 & Igualdade e equidade de condições de trabalho, direitos e salário, outros. \\
\hline 3 & $\begin{array}{l}\text { Mulher tem que trabalha pra ajuda seu companheiro dentro de casa e tem que te vaga em } \\
\text { creches }\end{array}$ \\
\hline 4 & $\begin{array}{l}\text { Acho que a educação é a base de tudo. E a maioria das mulheres deixam os estudos pra cuidar } \\
\text { de casa e filhos. Um projeto de inclusão dessas mulheres na escola e Universidade. Ninguém } \\
\text { pode com uma mulher bem instruída. E a questão do horário de funcionamento das creches. } \\
\text { Deveria funcionar das 7:00 às 19:00 }\end{array}$ \\
\hline 5 & $\begin{array}{l}\text { A saúde está sempre em primeiro lugar em tudo! Criar políticas públicas voltadas para a } \\
\text { mulher, onde ela possa se seja bem recebida desde a adolescência e possa fazer um } \\
\text { acompanhamento. Depois, sempre projetos com esportes, isso é muito importante para criar } \\
\text { uma geração melhor. }\end{array}$ \\
\hline 6 & $\begin{array}{l}\text { Programas de atividades físicas. . Programas direcionados aos filhos dessas mulheres. . } \\
\text { Atendimento maior na área de saúde da mulher pragamas q incluam mais a formação dessas } \\
\text { para o mercado de trabalho em áreas consideradas (só para homens ) diminuindo a falta de } \\
\text { emprego }\end{array}$ \\
\hline 7 & Valorização das pessoas \\
\hline 8 & $\begin{array}{l}\text { A democratização do processo politico , deixar transparecer, disseminar as informações, dar } \\
\text { oportunidade para o povo, deixar o povo participar , isso é importante. }\end{array}$ \\
\hline 9 & $\begin{array}{l}\text { Realizar um projeto de Qualidade de Vida no Trabalho e Promoção à Saúde da mulher, com } \\
\text { gestora desportiva e de lazer, com: médicas (psiquiatra e endocrinologista), educadoras físicas, } \\
\text { enfermeiras, psicólogas e estagiárias (educação física e nutrição). }\end{array}$ \\
\hline 10 & \begin{tabular}{l} 
Criar centros de atendimentos em todas as áreas, educação, saúde, trabalho social, etc. \\
\hline
\end{tabular} \\
\hline
\end{tabular}

Fonte: os autores.

Nesta questão também foram obtidas 10 respostas, como a anterior. Vemos que trabalho, educação e saúde rivalizam em prioridades para as políticas para mulheres. A questão de creches para o atendimento das mães aparece em duas respostas. A questão do atendimento à adolescente, tanto em questão de educação, saúde e até atividades físicas também aparece como importante. No entanto, muitas das propostas das candidatas à vereadora não são de competência do município, o que esbarra no fato de serem (a maioria das entrevistadas), iniciantes na política e nos pleitos. Além do mais, vemos que não há 
um foco de necessidades essencialmente femininas, mas sim de políticas que abrangem também as famílias e os homens, o que mostra que a política brasileira é precária a todos os cidadãos. Apenas na resposta 06 aparece a ideia de preparação da mulher para o trabalho em áreas tradicionalmente masculinas, resolvendo a falta de emprego entre as mulheres.

\section{Considerações finais.}

A participação da mulher na política, tanto nos níveis federal, estadual e municipal ou local ainda repousa em belos ideais que possuem fortes obstáculos tanto na sociedade, quanto na organização política brasileira. Tais obstáculos são desestimulantes e até mesmo hostis para a mulher que queira participar de uma eleição.

As condições que levam uma mulher a se candidatar na política local são várias, mas a questão da ajuda e do auxílio à comunidade é preponderante. As candidatas não falam da mulher especificamente, mas à sociedade como um todo. Por um lado, pode ser o lugar-comum do discurso político, mas pode ser também a precarização a que está submetido o aparelho estatal brasileiro, de modo generalizado. As candidatas também entendem que a participação feminina na política pois as diferenças observadas na mulher em relação ao homem (ser mais sensível, emotiva, honesta, maternal, etc.) deveriam ser privilegiadas pelo eleitor, pelo bem da comunidade. Ou seja, a percepção que a mulher é um "outro" na sociedade formada pelo patriarcalismo brasileiro, e não que comunga de uma mesma situação e destino histórico que o restante da sociedade (os homens) entra em conflito com os motivos para ser vereadora.

Assim, a participação da mulher na política é considerada baixa por culpa da própria mulher que não se interesse, ou porque esta participação está tão obstacularizada que coloca impeditivos imensos para a mulher. Podemos perceber que a Umuarama apelidada de "mulherama" não ficou presente a questão do machismo ou da objetificação nas falas das candidatas, exceto por uma única resposta. No entanto, há a percepção generalizada que a mulher não é valorizada em sua condição feminina nesta cidade. Podemos inclusive pensar a questão do nepotismo, onde a mulher tem uma certa facilidade na política conforme ela tenha uma família de tradicional peso político (especialmente entre os homens). Como em Umuarama não há a presença de mulheres nesta situação, isto não foi levantado em nossa pesquisa.

Pudemos perceber também a falta de projetos locais de valorização da mulher e da promoção de consciência política entre as mulheres. Podemos aqui dizer que falta de educação política é um problema grave de nossa cidadania, de modo generalizado. Em um país onde a educação básica ainda é um grave 
problema social, a formação para a cidadania e para a vida política acaba sendo prejudicado, e por tais motivos, a participação feminina ainda possua os grilhões do passado, refletindo nas eleições, a hostilidade social a que a mulher brasileira está diariamente submetida.

\section{REFERÊNCIAS}

BOURDIEU, P. (2010). A dominação masculina. 8.ed. Rio de Janeiro: Bertrand Brasil.

HARAWAY, D. (2004) . "Gênero" para um dicionário marxista: a política sexual de uma palavra. Cadernos Pagu n.22: pp.201-246. Disponível em: http://www.scielo.br/pdf/cpa/n22/n22a09.pdf. Acesso em 24 de nov. 2016.

MAIS MULHERES NA POLÍTICA. (s.d.) Senado federal e Procuradoria Especial da Mulher Disponível em https://www12.senado.leg.br/institucional/procuradoria/proc-publicacoes/2a-edicao-do-livreto-mais-

mulheres-na-politica. Acesso em: 25 de nov. 2016.

MOTA, F. \& BIROLI, F. (2014). O gênero na política: a construção do "feminino" nas eleições presidenciais de 2010. Cadernos Pagu n.43, jul-dez. Disponível em: http://www.scielo.br/pdf/cpa/n43/0104-8333-cpa43-0197.pdf. Acesso em 24 de nov. 2016.

SOW, M. (2009). A participação feminina na construção de um parlamento democrático. Revista Eletrônica do Programa de Pós-graduação. Centro de formação, treinamento e aperfeiçoamento da Câmara dos Deputados. Disponível em http://bd.camara.gov.br. Acessado em 25/09/2016.

VAZ, G. (2008). A participação da mulher na política brasileira: a lei de cotas. Monografia apresentada para o curso de Especialização em Processo Legislativo. Câmara dos Deputados. 65fl. Disponível em http://bd.camara.leg.br/bd/handle/bdcamara/5813. Acesso em 20 de out. 2016. 